\title{
THE PROBLEM-SOLVING PROCESS WITH SPECIAL APPLICATION TO THE CLINICAL SETTING
}

\author{
J.T. Makhathini \\ Address delivered at the Nursing Education Association Conference on Clinical Teaching : \\ Broederstroom - March 1992
}

I would like to thank the organisers for giving me an opportunity to participate at this conference.

I have been asked to speak on problem-solving. Problem-solving is regarded by many nursing theorists as the core of the practice of nursing. It is a complex skill with cognitive as well as perceptual components and is embedded in subject specific knowledge. Like many other nursing skills, problem-solving can be taught and evaluated.

The question arises: What kind of problems do nurses have to solve? Van Gundy (1981) gives the following useful classification:

(i) Well-structured problems, in which case all the information required to solve the problem is available. These types of problems can be solved using standard operating procedures. Example: A patient who comes in with an acute shortness of breath has to be given oxygen immediately.

(ii) Ill-structured problems, where the problem solver is provided with little or no information on the best way to solve the problem. This requires a creative approach. Example: A terminally ill patient who is obviously in severe pain but refuses to take analgesics.

(iii) Semi-structured problems fall between the other two types mentioned. A combination of standard operating procedures and creativity would be required to solve this type of problem.

All three types of problems are encountered in nursing practice. The question I would like to address in this paper is whether we, the nurse educators, are doing enough to develop the problem-solving skill in our students and whether this skill is being adequately evaluated.

In order to examine whether we are addressing the skill of problem-solving in our teaching, it is essential to have a clear understanding of what the skill entails. A mere definition would not tell us much about the concept of problem-solving whereas a concept analysis would serve to clarify the meaning of the concept.
Prior to the occurrence of problem-solving, there are certain events or incidents which must occur, which are referred to as antecedents.

\section{ANTECEDENTS include:}

(i) An ability to think critically.

(ii) The existence of a situation which hampers or retards progress or a situation or event which takes an unexpected or unintended course. It could be a situation in which a gap is perceived to exist between what is and what should be.

(iii) Knowledge and skill related to the problem area.

(iv) A willingness to take responsibility or get involved with the problem.

\section{CRITICAL ATTRIBUTES}

These are the essential features of the concept problem-solving. They include

(i) The recognition that a problem situation exists and that a reaction to it is needed.

Example: If a person in charge of a unit is unaware that there is a staff shortage in his/her department in the evenings, then no problem-solving will commence. Problem-solving will only take place after awareness develops and not before. There must also be a perceived need to solve the problem.

(ii) Generation of possible solutions to resolve the situation.

(iii) Selection and implementation of a course of action from amongst the alternatives generated, taking into consideration factors such as suitability and cost-effectiveness.

(iv) The problem-solver may or may not depart from routine procedure.

EMPIRICAL REFERENTS (for the critical attributes).

These are classes or categories which demonstrate the occurrence of problem-solving
This is what the clinical instructor should look out for, because it will indicate whether the student is actively problem-solving or not. These include:

(i) Looking for additional information which may take the form of extra observation, questions or looking at records, thus leading to recognition of a problem.

(ii) Action is taken that directly addresses the problem.

(iii) Recording a problem and the actions taken to solve it.

\section{CONSEQUENCES}

Consequences are events which occur as a result of problem-solving. They include:

(i) Problem resolution characterised by a return to the desirable state of affairs.

(ii) Continuation of the problem.

Problem-solving is not always followed by problem resolution. This may be the result of the quality of the problem-solving process or the quality of the problem.

To illustrate clearly what problem-solving means, I shall use, firstly, a model case which is a "real life" example of the concept problem-solving; secondly, a contrary case, which is a clear example of what problem-solving is not, since some people find it easier to say what something is not rather than what it is and thirdly, a borderline case which contains some of the critical attributes of the concept being examined, in this case, problem-solving.

\section{MODEL CASE}

A model case is a "real life" example of the concept and includes all the critical attributes.

Example: Patient $X$ is mentally retarded and has been admitted for tubal ligation. The ward is divided into four sections and each section has its own team of doctors. On this particular day, Patient X's relatives requested a passout to enable her to fetch her disability grant. Unfortunately, the patient's doctor was not available on this day. Rather than the patient missing her disability grant, the professional 
nurse in charge of the patient decided to ask a doctor from another section to sign the patient's passout. This is not normal procedure, but because of the professional nurse's good human relations and creativity, the passout was signed and the patient was able to fetch her disability grant.

This is a model case of the concept "problem-solving" because all the critical attributes have been met.

\section{CONTRARY CASE}

$A$ contrary case differs radically from the concept in question; in our case, problem-solving.

Example: Patient $Y$ has had a normal vaginal delivery. The infant is a healthy baby girl weighing 3,5 kilograms. Patient $Y$ was immediately transferred to a post-natal ward as she did not have any post-delivery complications at that stage. Two hours later, however, the patient reported to her professional nurse that she thought she was having excessive vaginal bleeding. The professional nurse instructed the patient to change the sanilary pads regularly. An hour later, the patient complained of dizziness. She was instructed not to get out of bed.

Two hours thereafter, the patient tried to get out of bed in order to get a fresh supply of sanitary pads when she started passing massive blood Jots vaginally and then collapsed. A doctor was called to resuscitate the patient. This was not successful and the patient died about fifteen minutes later

This is a contrary case, since the professional nurse failed to recognise the problem and consequently gave non-specific orders which did not help the patient. If we look at point (ii) professional nurse takes actions, they are not effective because they do not address the real problem.

\section{BORIDERLINE CASE}

$\wedge$ borderline case contains some of the critical attributes of the concept being examined, but not all of them.

Example: There is a staff shortage in Unit $X$ over weekends and public holidays because the senior staff members are not willing to work during these periods. The quality of patient care suffers as a result of this problem. To solve the problem, the Nursing Service Manager decides to bring in part-lime staff during the periods in question, even though this is very expensive and the quality of patient care does not improve significanily since part-time personnel are not familiar with the unit.

This is a borderline case because the suitability and cost-effectiveness of the option taken have not been considered. It is also questionable whether the problem of the quality of patient care has been resolved. Al other attributes have been met.

In addition to the three cases there are:

\section{RELATED CONCEYTS}

These concepts are related to problem-solving but do not contain the critical attributes.

\section{(i) Decision-making}

A decision is the conclusion of a process by which one chooses among available alternatives for the purposc of achieving a set of desired objectives.

Decision-making creates systems for rational comparison of options so as to pick the best one in terms of its effectiveness in achieving the goal with efficiency.

Decision-making can thus be seen as a phase in the problem-solving process; however, not all decisions are of a problem-solving nature, such as decisions about budgets or equipment. Also a major decision may have involved the solving of several related problems.

\section{(ii) Creativity}

Creativity refers to the ability to develop and implement new and better solutions.

A creative person is constantly seeking alternate and new ways of defining or interpreting a problem so as to generate new and better strategies to resolve the problem.

Creativity may be blocked when people remain locked into particular definitions of problems even though these are obviously unfruitful, or when people become so personally involved in their own approach to a particular problem that they have difficulty considering other alternatives.

\section{(iii) Critical Thinking}

Critical thinking involves the evaluation of ideas. $A$ critical thinker asks questions, seeks evidence, examines different alternatives and criticises his or her own ideas and those of others.

A critical thinker does not accept statements outright but instcad sceks reasons for supporting them. A student who engages in critical thinking can decide for himself which ideas to accept and which to reject and he can provide the reasons underlying his decisions.

This ultimately leads to better and more effective reasoning. Critical thinking represents the thought process underlying problem-solving and decision-making.

\section{(iv) Data Collection}

The purpose of information gathering is to assemble existing information, to monitor, control and evaluate a situation.

II is a routine occurrence and the methods used are recording and reporting.

Data collection techniques ate fixed and standardised.

Data analysis consists of description only and the depth of analysis seldom goes beyond description.

The skills required are dala and data systems management and processing.
Nurses are involved with data collection on a daily basis, e.g. statistics on admissions, readmissions, births, deaths etc. The maintenance of impressive records and graphs reflecting the statistics mentioned above would be a futile exercise if all that valuable information is not used to identify and solve problems in the unit concerned.

This concludes the process of problem-solving.

During their first years of training our students are introduced to the theory of clinical problem-solving in the form of the nursing process, however, the practical application of this theory in the clinical situation has been seen to be less than satisfactory. According to Chang (1991), the reasons for the incomplete use of the nursing process can be classified according to:

\section{- cognition \\ - skill and \\ - attitudes}

The general feeling is that clinical problem-solving is too difficult, 100 theoretical and too time consuming.

Effective problem-solving in nursing requires theoretical as well as procedural knowledge of both the problem-solving process itself and the principles and process of nursing. In other words, learning how to solve problems in nursing involves acquiring knowledge of and skill in problem-solving as well as integrating this with the acquisition of nursing knowledge and skill.

\section{WIIAT ARE THIE IMPLICATIONS OF THE PROBLEM-SOLVING PROCESS FOR CLINICAL TEACIIING?}

Reilly and Oerman (1985) identify seven principles for teaching problem-solving, namely:

- The nature of the problem selected for student involvement needs to be at an appropriate level in terms of the learner's knowledge base.

- Learners, because of their limited practical knowledge and experience in the clinical ficld should be assisted in identifying and delimiting problems.

- Learners need assistance in identifying multiple solutions for problems. This promotes cognitive development and divergent thinking and also improves the change of finding the best and more appropriate solution for the problem. The teacher needs to support the student during this process.

- It is important for the learners to follow a sequence of steps from definition of the problem to evaluation of solutions so as to maintain the integrity of the problem-solving process even though in reality the process may not follow a sequence of sieps. 
- The emphasis in teaching problem-solving should be on the process itself rather than on the outcomes.

- In addition to the analytic process of problem-solving, the leamers also should be taught the importance of recognizing hunches and searching for evidence to confirm or reject them.

- The teacher should be supportive and tolerant of differences among leamers in their approaches to problem-solving.

In addition to the seven principles, good role modelling has been identified by many nurse authors, such as Robertson (1980), as an effective teaching strategy in the clinical area. Students should be afforded an opportunity to actually observe the problem-solving process in action either from the clinical instructor or the preceptor. Students should, however, be critical of everything observed, as blind acceplance could be dangerous.

The clinical teacher should realise that it is not enough just to ensure that the student knows how to do the nursing procedure, but the student should be able to relate the nursing care to the patient's presenting problems and the nursing care must be seen as a solution to the patient's problem and not just a routine procedure. The student should be stimulated to take an active part in his/her learning by the teacher asking questions such as:

- Why is a particular nursing care being done?

- Why is it being done in this particular way?

- What would be the consequences of not performing the nursing care?

An effort on the part of the student and the clinical teachers should be made to exploit the full potential of the clinical setting with regard to the teaching and leaming of the process of problem-solving.

\section{WHAT ARE THE IMPLICATIONS OF THE PROBLEM-SOLVING PROCESS FOR THE CLINICAL EVALUATION OF STUDENT PERFORMANCE?}

Whether or not we are evaluating our students problem-solving skill adequately depends largely on our approach to the process of evaluation. Perhaps if we reflect on the process of problem-solving as described earlier, we could ask ourselves the following questions:

- Are we evaluating our students' ability to recognise problem situations and then ask relevant questions?

- Are we testing the ability to generate solutions to resolve the situation?

- Do we check if the actions taken to resolve the situation are appropriate?
These and other questions may be asked to determine if our evaluation strategies are geared towards evaluating the students effectiveness in problem-solving.

To this end, the McMaster University (Canada) programme could serve as a useful example. The programme facilitates self-directed learning and self-evaluative and problem-solving skills.

In addition to the conventional methods of student evaluation, the "Triple Jump" method, designed specifically to evaluate the student's problem-solving ability is employed.

It consists of three steps namely:-

\section{STEP 1 - Problem Definition - 1/2 hour}

The student is presented with a problem nursing situation from which to identify nursing problems.

The student then proceeds to gather data from the history and physical examination. The examiner reads this information from the chart and gives it to the student. The patient's problems are then summarised by the student to arrive at an interim problem formulation.

The student then identifies nursing interventions for the problems identified.

At this point the student is asked to pinpoint important gaps in her knowledge or understanding of relevant information, e.g. it could be the anatomy and physiology related to the patient's problem.

\section{STEP 2 - Independent Study - 2 hours}

This is done to enable the student to bridge the knowledge gap. The student is advised that on return she will be asked to revise the problem list based on any additional information and further to develop one problem with short and long term goals, nursing interventions with rationales for the interventions.

STEP 3 - Synthesis and Integration - 45 minutes

The student is asked if there are any changes in the problem formulation. The problems must be stated in their order of priority, the reasons for stating the problems must be specified. The student is asked how the issues were researched, what resources were consulted and the time spent. Finally the student evaluates her own performance. The entire exercise is evaluated and a score is awarded.

\section{CONCLUSION}

If we are still having problems with the implementation of clinical problem-solving, then maybe we need to take a second look at our teaching and evaluation strategies in relation to problem-solving to determine ways in which we could bring about an improvement in this important area of nursing practice. I see this as a challenge to all of us. We have an obligation to prepare professionals who will be able to function as independent practitioners endowed with the skill to critically analyse and evaluate information.

\section{REFERENCES}

CHANG A.M. AND GASKILL D. Nurses' perceptions of their problem-solving ability. (1991). Journal of Advanced Nursing. 16, 7, 813-19.

HENGSTBERGER-SIMS, C. AND MCMILLAN, M.A. (1991). Stakeholder evaluation: A model for decision making in problem-based learning. Nurse Education Today. 11, 6, 439-47.

HINCHLIFF S.M. (ed) (1979). Teaching Clinical Nursing. Churchill Livingstone: London: Churchill Livingstone.

HURST, K., DEAN A. AND TRICKEY S. (1991). The recognition and non-recognition of problem-solving stages in nursing practice. Journal of Advanced Nursing. 16, 12, 1444-55.

MORGAN, S.A. (1991). Teaching activities of clinical instructors during the direct client care period: a qualitative investigation. Journal of Advanced Nursing. 16, 10 1238-46.

REILLY, D.E. AND OERMAN, M.H. (1985). The Clinical Field. Norwalk, Connecticut: Appleton Century Crofts.

ROBERTSON, C.M. (1980). Clinical Teaching. London: Pitman.

SULLIVAN, EJ. AND DECKER, P.J. (1988). Effective Management in Nursing. Second Edition. New York: Addison-Wesley.

VAN GUNDY, A.B. (1981). Techniques of Structured Problem-solving. New York: Van Nostrand Reinhold.

WALKER, L.O. AND AVANT K.C. (1983) Strategies for Theory Construction in Nursing. U.S.A.: Appleton Century Crofts.

Ms. J.T. Makhathini

Edendale Nursing College 